\title{
Preparation and detailed characterization of fusidic acid loaded in situ gel formulations for ophthalmic application
}

\author{
Seda RENÇBER 1 (D), Ece ÖZCAN BÜLBÜL 2 (D), Neslihan ÜSTÜNDAĞ OKUR ${ }^{*}{ }^{*}(\mathbb{D}$, \\ Zeynep AY ŞENYİĞİT 1 (D)
}

1 Department of Pharmaceutical Technology, Faculty of Pharmacy, İzmir Katip Celebi University, Izmir, Turkey.

2 Department of Pharmaceutical Technology, Faculty of Pharmacy, İstinye University, İstanbul, Turkey.

3 Department of Pharmaceutical Technology, Faculty of Pharmacy, University of Health Sciences, İstanbul, Turkey.

* Corresponding Author. E-mail: neslihanustundag@yahoo.com(N.Ü.O.); Tel. +90-216-418 9616.

Received: 22 October 2020 / Revised: 10 December 2020/ Accepted: 11 December 2020

ABSTRACT: This study aimed to assess the potential usage of fusidic acid in situ ocular gels for bacterial conjunctivitis treatment. The in situ gelling systems were applied to improve the bioavailability and residence time of fusidic acid in the ocular mucosa. Temperature-triggered in situ ocular gel formulations were prepared by the cold method with Poloxamer 407 and sodium carboxymethyl cellulose. The in situ gels were evaluated for $\mathrm{pH}$, clarity, gelation temperature, rheological properties, mechanical properties, and in vitro drug release. The gelation temperatures of fusidic acid loaded the formulations were between $29-33^{\circ} \mathrm{C}$. All prepared in situ gels showed nonNewtonian pseudoplastic flow (shear thinning system) like tear fluid at $32 \pm 0.1^{\circ} \mathrm{C}$. The results of in vitro dissolution studies showed that at least $65 \%$ of fusidic acid released in 12 hours. As a result of this study, it was concluded that fusidic acid loaded in situ gels might be offered as a promising ocular tool for the treatment of bacterial conjunctivitis.

KEYWORDS: Fusidic acid; in situ gel; poloxamer; NaCMC; ocular.

\section{INTRODUCTION}

The physiology and anatomy of the eye render is exquisitely impermeable to foreign substances and drugs. Most of the eye diseases are treated with topical formulations such as eye drops or ointments. However, conventional ocular formulations could generate blurred vision or eye irritation while different ocular barriers might induce nasolacrimal drainage system, lachrymation and enzymatic metabolism [1]. Therefore, novel ocular formulations are designed aiming to enhance bioavailability of drugs by prolonging the retention time since low ocular bioavailability is a result of drug loss from eye surface due to tear fluid secretion as well as blood-eye barriers [2].

In situ gels are aqueous solutions that transform to gel-form under physiological conditions after administration. There are varied mechanisms such as ionic cross-linkage, temperature modulation, and $\mathrm{pH}$ change that bring about in situ gel formation [3]. By now, several natural and synthetic polymers have been applied for the preparation of in situ gels [4]. Ophthalmic preparations are sterile, liquid, semi-solid, or solid preparations that may contain one or more active pharmaceutical ingredients. Sterility is a key issue in the use and manufacture of ophthalmic products [5,6]. Sterilization is divided into two major categories, aseptic and terminal $[7,8]$. Aseptic sterilization is employed when the dosage form does not allow other sterilization methods to be used [5]. Terminal sterilization refers to the sterilization of the final formulation. Terminal sterilizations are steam heat (with autoclaving $15 \mathrm{~min}$ at $121-124^{\circ} \mathrm{C}$ ), dry heat $\left(30 \mathrm{~min}\right.$ at $\sim 180^{\circ} \mathrm{C}$ ), ionizing radiation (gamma irradiation), chemical sterilization (with ethylene oxide) [8,9]. If the ophthalmic preparation has a size below $200 \mathrm{~nm}$, it is possible to conduct aseptic filtration. Larger particles must be sterilized by terminal sterilization methods [10]. But, these methods can negatively affect several material properties (e.g., aspect, mechanical integrity, chemical structure, size, color, and biocompatibility) [11]. The presence of water in gels exacerbates some of the destructive effects of sterilization [8]. Because of the hightemperature range, autoclaving often generate aggregation of particles, changes in their biological activities, and can melt the polymer or alter its morphological structure $[7,10]$. Ethylene oxide is less recommended due to the toxicity and carcinogenicity of its residues. Finally, gamma sterilization is the most popular

How to cite this article: Rençber S, Özcan Bülbül E, Üstündağ Okur N, Ay Şenyiğit Z. Preparation and detailed characterization of fusidic acid loaded in situ gel formulations for ophthalmic application. J Res Pharm. 2021; 25(1): 1-12. 
procedure for the sterilization of heat-sensitive materials [7]. Because it utilizes neither heat nor chemicals, avoiding toxic residues after sterilization [10]. Thermosensitive drugs can be sterilized by membrane filtration of their solutions followed by crystallization and incorporation into the steam-sterilized polymer formulation under aseptic conditions. Preservatives are added to multidose ophthalmic preparations to maintain their microbiological qualities during use [12]. In several studies in which ophthalmic in situ gels were prepared; it has been reported that autoclaving sterilization does not change the physicochemical properties such as $\mathrm{pH}$ value, drug content, flowability, flow behavior, and sol-gel transition temperature [13], causes chemical degradation of the active pharmaceutical ingredient even though its sol-gel transition temperature has not been changed [14], and gamma radiation in the presence of dried ice is used to protect from autoclaving destruction [15]. In a study comparing sterilization methods, it was found that sterile filtration affected the rheological properties the least, and longer autoclaving at low temperature can prefer over short-term autoclaving at high temperature [16].

Fusidic acid (FA) is a widely used steroidal bacteriostatic antibiotic drug with a tetracyclic ring. It has been successfully used for the treatment of infections caused by Gram-positive species and especially Staphylococcus aureus $[17,18]$. Its bioavailability is rate-limited with its dissolution and it is a Biopharmaceutics Classification System (BCS) Class-II drug[4]. It is formed in numerous formulations for oral (suspension and tablet), topical (cream and ointment), and intravenous administration [19]. Commercial ocular formulations of FA are widely used for the topical treatment of bacterial conjunctivitis[20].

This study targeted to prepare and optimize a FA loaded in situ gel formulation for the remedy of superficial conjunctiva and eye infections.In situ gel was prepared with Poloxamer (PLX) 407 and combined with sodium carboxymethyl cellulose $(\mathrm{NaCMC})$ to improve its bioadhesive properties. The in situ gels were detailly characterized in terms of their suitability for ocular use.

\section{RESULTS AND DISCUSSION}

The role of the polymers in ocular products is to improve the bioavailability and permeability of drugs by increasing the residence time on the eye surface. Ophthalmic in situ gels are liquid at room temperature and forms a gel at a body temperature defined as the gelling temperature. Pluronics, called Poloxamers, is one of the well-known types of polymers that have thermoresponsive behavior. PLX 407 is a suitable triblock polymer for ophthalmic administration due to its low toxicity, reverse thermosensitive gelation, mucomimetic property, controlled drug delivery, and optical clarity. Therefore it has been used favorably for different ocular diseases [21]. However, the low mucoadhesive activity of PLX 407 is its major disadvantage and restricts its widespread use.In the literature, some Pluronic-based preparations have been prepared by using additional mucoadhesive polymers. In the current study, NaCMC has been used to improve gel reliability, strength, and physicochemical properties due to its gelling and mucoadhesive properties [22,23].

\subsection{Preparation of formulations}

In the present investigation, gels were successfully formulated by a cold technique using different concentrations of PLX 407 and NaCMC. All in situ gels showed good homogeneity without lumps. All formulations have satisfactory clarity. After the preparation, the in situ gels were examined in terms of many parameters such as $\mathrm{pH}$, gelling capacity, rheological/mechanical properties, and in vitro drug release.

\subsection{Acidity}

Acidity is an important parameter in the ophthalmic administration of formulations. The $\mathrm{pH}$ value of all gelswas found to be in the range of 6.2-7.0, which is acceptable for ophthalmic preparations (Table 1) $[24,25]$. Similarly, Patel et al. [26] prepared in situ ocular gel formulations containing hydroxyl propyl methyl cellulose and PLX 407 and found pH values between 6.8 and 7.4. Guven et al. [27]prepared ocular extendedrelease in situ gels against ocular allergy and the $\mathrm{pH}$ value of these formulations was found between 6.50 and 7.00, which was suitable for ocular use.

\subsection{Measurement of gelation temperature}

Ocular in situ gelling systems should be low viscosity free-flowing liquid between $4^{\circ} \mathrm{C}$ and $25^{\circ} \mathrm{C}$ to allow the administration as eye drops. After the administration; they should also undergo in situ phase transition to form a clear gel in eye temperature [28]. 
Pluronics or PLXs are triblock copolymers of propylene oxide (PO) and ethylene oxide (EO). The $\mathrm{PEO} / \mathrm{PPO}$ weight ratio determines the amphiphilic properties. In aqueous solutions, PLX 407 molecules selfassemble in micelles at the critical micellization temperature because of the dehydration of PPO blocks. Insitu gel-forming systems have been developed using PLX 407 and a different polymeric additive such as cellulose derivatives[22,23,29]. In this study, $\mathrm{NaCMC}$ was selected as a cellulose-based additive polymer due to its better gelling capacity, mucoadhesiveness, and biocompatibility. Aqueous solutions containing PLX 407 and NaCMC combinations were prepared and evaluated in terms of their suitability for in situ gelforming systems. The gelation temperature values of the gel formulations are demonstrated in Table 1.

Table 1.pH values and gelation temperatures of formulations.

\begin{tabular}{lcc}
\hline $\begin{array}{l}\text { Formulation } \\
\text { Code }\end{array}$ & $\mathbf{p H} \pm$ S.D. & $\begin{array}{c}\text { Gelation temperature } \\
\left({ }^{\circ} \mathbf{C}\right) \pm \text { S.D. }\end{array}$ \\
\hline F1 & $6.81 \pm 0.004$ & $37.016 \pm 0.019$ \\
F2 & $6.46 \pm 0.007$ & $35.736 \pm 0.025$ \\
F3 & $6.79 \pm 0.006$ & $32.440 \pm 0.036$ \\
F4 & $6.53 \pm 0.006$ & $32.748 \pm 0.038$ \\
F5 & $6.58 \pm 0.007$ & $23.909 \pm 0.018$ \\
F6 & $6.52 \pm 0.008$ & $24.112 \pm 0.016$ \\
F7 & $6.77 \pm 0.005$ & $21.762 \pm 0.019$ \\
F8 & $6.65 \pm 0.006$ & $20.794 \pm 0.021$ \\
F3+FA & $6.23 \pm 0.007$ & $29.847 \pm 0.028$ \\
F4+FA & $6.22 \pm 0.006$ & $32.534 \pm 0.032$ \\
\hline
\end{tabular}

The gelation temperatures ofF1-F4 formulations containing the mixture of PLX 407 (12-14\%) and Na$\mathrm{CMC}(0.1-0.5 \%)$ were found between $32^{\circ} \mathrm{C}$ and $37^{\circ} \mathrm{C}$. In situF5-F8 gel formulations containing the mixture of PLX $407(16-18 \%)$ and NaCMC $(0.1-0.5 \%)$ had low gelation temperatures $20.794 \pm 0.021^{\circ} \mathrm{C}$ to $24.112 \pm 0.016^{\circ} \mathrm{C}$, respectively. Karataş et al. [28] developed in situ gels containing PLX and chitosan for ocular delivery. To increase the gelation temperature, the concentration of PLX was decreased to $15 \%$ and gelation temperatures were found to be $34^{\circ} \mathrm{C}$.

The gelation temperatures of F3 and F4 formulations containing the same ratio of PLX $407(14 \%)$ and $0.5 \%$ to $1 \% \mathrm{NaCMC}$ showed appropriate gelation temperatures as $32.440^{\circ} \mathrm{C}$ and $32.748^{\circ} \mathrm{C}$, respectively. Both of these formulations had a clear and homogeneous appearance. Therefore, they were selected as the optimum formulation.

The addition of FA to F3 formulation decreased the gelation temperature to $29.847 \pm 0.028^{\circ} \mathrm{C}$. Li et al. reported that the addition of tea polyphenols as an anti-inflammatory agent to thermosensitive in situ gels ( $25 \%$ of poloxamer $407,5 \%$ of poloxamer 188 , and $0.1 \%$ of carbazole 940 ) increased the gelation temperature from 29.1 to 29.4 (before contact to stimulated fluid) and from 35.4 to 35.5 (after contact to stimulated fluid) insignificantly. Similarly, in our study, the addition of FA to F4 formulation didn't significantly decreased the gelation temperature[30].

\subsection{Rheological studies}

The rheological measurements indicated that each formulation exhibited non-Newtonian pseudoplastic flow (shear thinning system) as like as tear fluid at $32 \pm 0.1^{\circ} \mathrm{C}$. Non-Newtonian behavior is observed specifically for PLX gels above the sol-gel transition temperature[31,32]. It was found in the literature that in situ gel systems generally showed shear thinning behavior at body temperature $[27,33,34]$. Also, all formulations demonstrated a Newtonian flow at $25 \pm 0.1^{\circ} \mathrm{C}$.In the pseudoplastic flow, viscosity reduces with an increase in shear rate.The concentration of PLX 407 has an important effect on the viscosity of the gels. As the concentration of PLX 407 increased from 12\% to 18\%, the viscosity of the gels increased from 0.507 to $33.617 \mathrm{~Pa} . \mathrm{s}$ at $32 \pm 0.1^{\circ} \mathrm{C}$. Also, when the concentration of $\mathrm{NaCMC}$ was increased in the in situ gels, the viscosity was increased (Figure 1).

The elastic storage $\left(G^{\prime}\right)$ and viscous loss $\left(G^{\prime \prime}\right)$ moduli vs. frequency profiles of formulations were reported in Figure 2. All prepared in situ gels were exhibited higher $G^{\prime}$ values than $G^{\prime \prime}$, indicating a prevalence of the elastic on the viscous contribution at $32^{\circ} \mathrm{C}$. This indicates the capability of formulations to respond elastically to deformation (i.e., to partially recover deformation upon stress removal) and then of protecting ocular lesions. 
The value of phase angle $\left(\tan \delta=G^{\prime \prime} / G^{\prime}\right)$, which is a measure of the relative contribution of viscous components to the mechanical properties of the materials, was <1 for F3, F4, F5, F6, F7, F8, and F3+FA coded formulations (solid gel response), but was $>1$ for F1, F2 and F4+FA coded formulations at $32^{\circ} \mathrm{C}$ (liquid-like response) due to higher gelation temperature (Table 2).

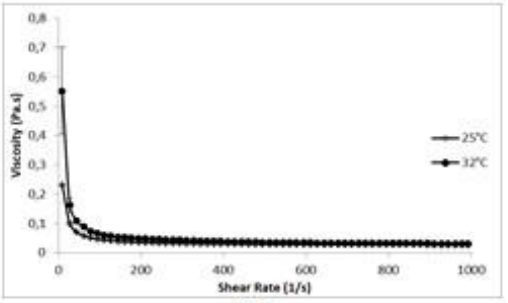

F1

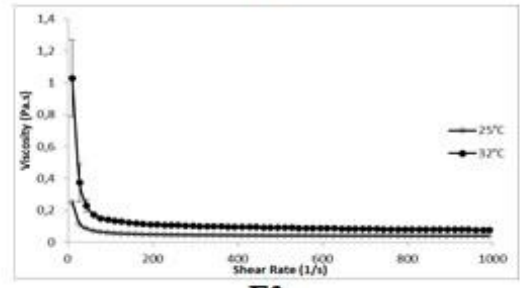

F3
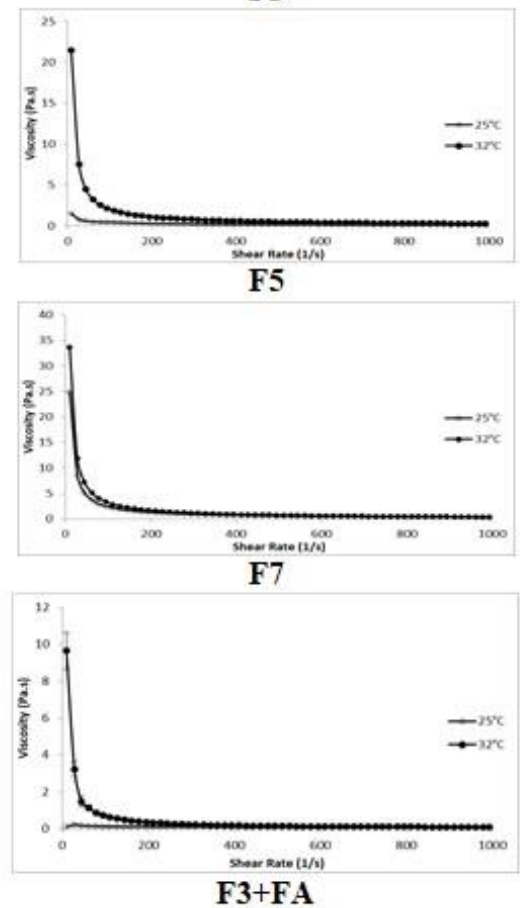

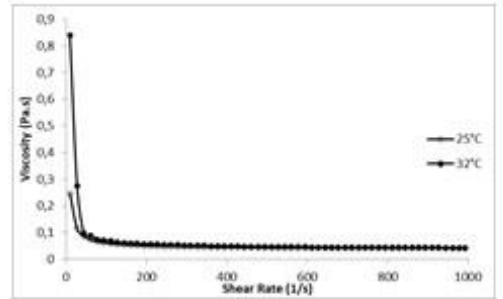

F2

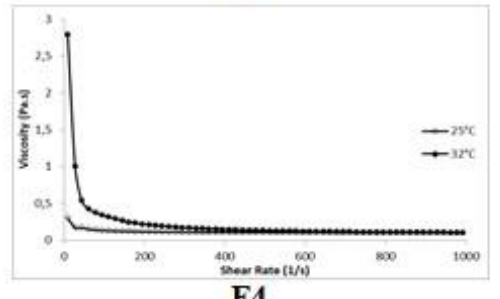

F4
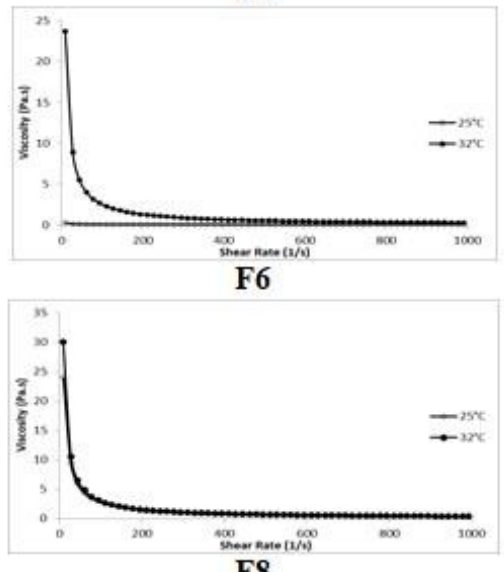

F8

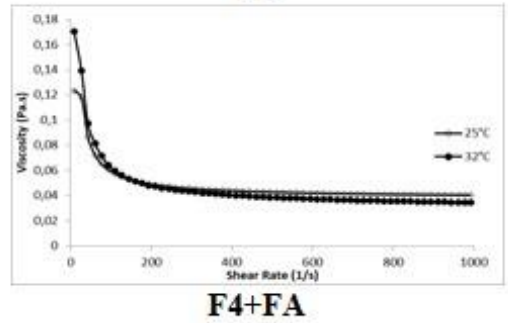

Figure 1. Viscosity values of the gels at $25^{\circ} \mathrm{C}$ and $32^{\circ} \mathrm{C}$.

\subsection{Determination of mechanical properties}

Ocular in situ gel formulations should have suitable mechanical properties for high spreadability on the ocular mucosa, easy administration, and strong adhesion. The mechanical properties were characterized under compressive stress and subsequent relaxation with Texture profile analysis (TPA) and the obtained results were given in Table 3.

The hardness value expresses the easy applicability of the gel to the ocular surface and it should not be too high not to prevent easy administration and spreadability. As can be seen from the table, the hardness value of the gels increased significantly as the PLX 407 ratio increased. Similarly, Swain et al. expressed that the hardness of the formulation increases as the concentration of polymer increases for their in situ gel formulations [35]. 


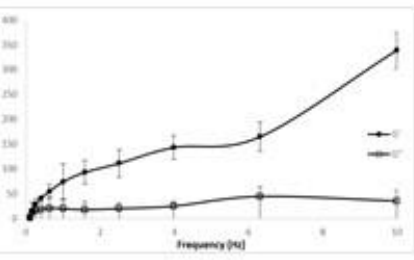

F1

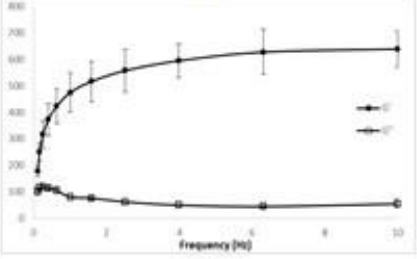

F3

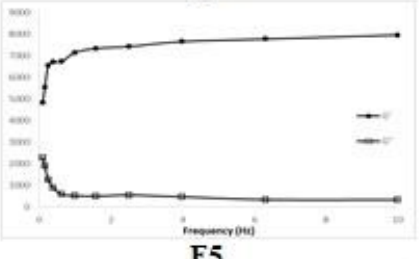

F5

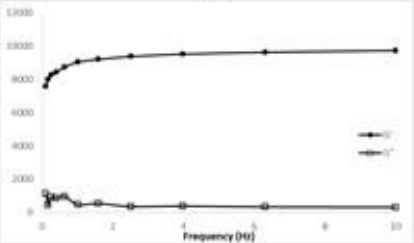

F7

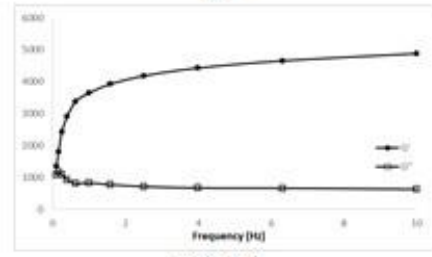

F3+FA

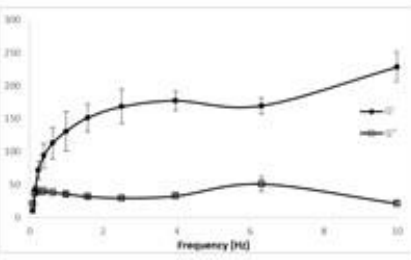

F2

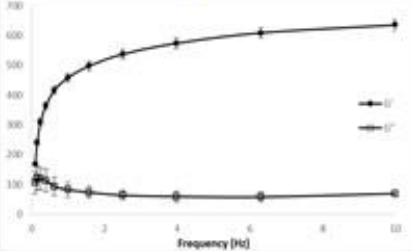

F4

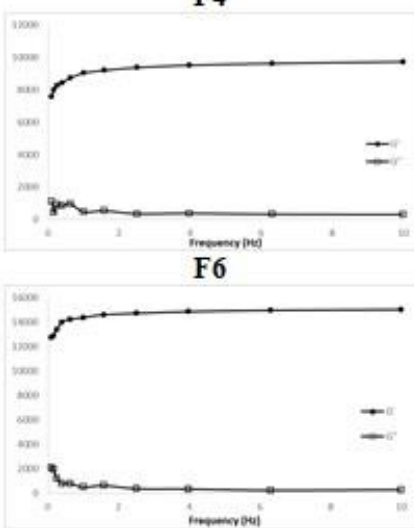

F8

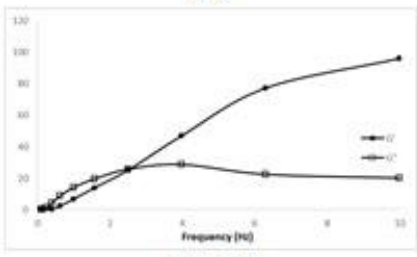

F 4+FA

Figure 2. Frequency-dependent changes of viscoelastic properties of the gels at $32^{\circ} \mathrm{C}$.

Table 2. Effect of temperature on the loss tangent $(\tan \delta)$ of the gels at $32^{\circ} \mathrm{C}$.

\begin{tabular}{ccccc}
\hline $\begin{array}{c}\text { Formulation } \\
\text { Code }\end{array}$ & $\mathbf{5 . 1 0} \mathbf{~ H z}$ & $\mathbf{0 . 6} \mathbf{~ H z}$ & $\mathbf{4 ~ H z}$ & $\mathbf{1 0} \mathbf{~ H z}$ \\
\hline F1 & $4.007 \pm 0.082$ & $0.708 \pm 0.049$ & $0.281 \pm 0.087$ & $0.186 \pm 0.017$ \\
F2 & $2.118 \pm 0.055$ & $0.342 \pm 0.036$ & $0.194 \pm 0.071$ & $0.093 \pm 0.002$ \\
F3 & $0.573 \pm 0.009$ & $0.247 \pm 0.014$ & $0.085 \pm 0.013$ & $0.072 \pm 0.013$ \\
F4 & $0.634 \pm 0.020$ & $0.223 \pm 0.013$ & $0.103 \pm 0.010$ & $0.114 \pm 0.033$ \\
F5 & $0.472 \pm 0.022$ & $0.187 \pm 0.024$ & $0.066 \pm 0.001$ & $0.043 \pm 0.000$ \\
F6 & $0.496 \pm 0.007$ & $0.112 \pm 0.002$ & $0.113 \pm 0.006$ & $0.057 \pm 0.000$ \\
F7 & $0.151 \pm 0.036$ & $0.116 \pm 0.068$ & $0.040 \pm 0.000$ & $0.032 \pm 0.001$ \\
F8 & $0.095 \pm 0.001$ & $0.036 \pm 0.000$ & $0.024 \pm 0.002$ & $0.020 \pm 0.000$ \\
F3+FA & $0.803 \pm 0.090$ & $0.237 \pm 0.016$ & $0.151 \pm 0.025$ & $0.128 \pm 0.019$ \\
F4+FA & $7.434 \pm 0.023$ & $2.843 \pm 0.052$ & $0.613 \pm 0.005$ & $0.209 \pm 0.009$ \\
\hline
\end{tabular}


Table 3. Mechanical properties of the gels at $32^{\circ} \mathrm{C}$.

\begin{tabular}{lccccc}
\hline $\begin{array}{l}\text { Formulation } \\
\text { Code }\end{array}$ & $\begin{array}{c}\text { Hardness } \\
\text { (g) } \pm \text { SD }\end{array}$ & $\begin{array}{c}\text { Compressibility } \\
\text { (g.sec) } \pm \text { SD }\end{array}$ & $\begin{array}{c}\text { Adhesiveness } \\
\text { (g.sec) } \pm \text { SD }\end{array}$ & $\begin{array}{c}\text { Cohesiveness } \\
\pm \text { SD }\end{array}$ & $\begin{array}{c}\text { Elasticity } \\
\pm \text { SD }\end{array}$ \\
\hline F1 & $*_{-}$ & - & - & - & - \\
F2 & $*_{-}$ & - & - & - & - \\
F3 & 0.032 & 0.048 & 0.056 & 1.262 & 1.394 \\
& \pm 0.005 & \pm 0.013 & \pm 0.014 & \pm 0.172 & \pm 0.279 \\
F4 & 0.025 & 0.045 & 0.043 & 1.429 & 1.251 \\
& \pm 0.001 & \pm 0.008 & \pm 0.004 & \pm 0.016 & \pm 0.101 \\
F5 & 0.171 & 0.336 & 0.357 & 0.918 & 1.555 \\
& \pm 0.001 & \pm 0.012 & \pm 0.013 & \pm 0.013 & \pm 0.261 \\
F6 & 0.110 & 0.236 & 0.260 & 0.856 & 1.445 \\
& \pm 0.003 & \pm 0.046 & \pm 0.042 & \pm 0.026 & \pm 0.138 \\
F7 & 0.209 & 0.443 & 0.444 & 0.948 & 1.632 \\
& \pm 0.012 & \pm 0.091 & \pm 0.071 & \pm 0.038 & \pm 0.314 \\
F8 & 0.195 & 0.423 & 0.443 & 0.914 & 1.640 \\
& \pm 0.002 & \pm 0.017 & \pm 0.009 & \pm 0.021 & \pm 0.051 \\
F3+FA & 0.016 & 0.041 & 0.045 & 1.054 & 1.157 \\
F4+FA & \pm 0.001 & \pm 0.006 & \pm 0.0015 & \pm 0.151 & \pm 0.177 \\
\hline
\end{tabular}

* Could not be measured due to the low mechanical properties

Although the hardness value was increased, it was observed that this value did not adversely affect the application and spreading of the formulation. The hardness values of the formulations seem to be compatible with the results obtained from rheological studies. Similarly, the viscosity and hardness values of $\mathrm{F} 1, \mathrm{~F} 3$, F5, and $\mathrm{F} 7$ formulations at $32^{\circ} \mathrm{C}$ increase respectively as $\mathrm{F} 1<\mathrm{F} 3<\mathrm{F} 5<\mathrm{F} 7$. It is also seen that the addition of $\mathrm{NaCMC}$ to the formulations does not make a significant difference in the hardness value at $32^{\circ} \mathrm{C}$.

The compressibility value briefly shows the sample deformation under compression. It provides the easy removal of the formulation from the container. Also, it is an indicator of the spreadability of the application area. It was observed that the compressibility value increased in the same order with the viscosity and hardness results with the increasing PLX 407 ratio. In the visual inspection, it was concluded that this value was not too high to prevent the formulation from coming out of the container or spreadability at the application site [36,37].

Adhesiveness value defines the required work for detaching the probe from the formulation and higher adhesiveness indicates greater drug retention time at the tissue surface. Based on the results it can be seen that the highest adhesiveness value was obtained with F7 and F8 formulations, which also showed high hardness and compressibility properties. Remarkably, it was stated that increasing the concentration of $\mathrm{NaCMC}$ in the formulations from $0.1 \%$ to $0.5 \%$ did not significantly alter the adhesiveness results, even slightly reduced this value. It is seen that increasing the NaCMC ratio slightly decreased the hardness and compressibility values as well. Similarly, Abouhussein et al. found a lower value of hardness and compressibility for their in-situ gel formulations as NaCMC increases[38].

Cohesiveness shows the effect of repeated stress and elasticity represents the return speed of the deformed sample to its beginning form. The lower values indicate greater product elasticity $[36,37]$. Although F3 and F4 showed higher cohesiveness and elasticity, there was no significant difference among the other formulations.

The data obtained from TPA studies showed that the mechanical properties of F7 and F8 are higher compared to other formulations. However, the gelling temperature of these formulations was found to be around $20^{\circ} \mathrm{C}$. Similarly, F5 and F6 formulations turned into gel form at around $24^{\circ} \mathrm{C}$. For this reason, they were excluded from further studies. Also F1 and F2 formulations were removed from the study due to their very low mechanical properties and gelation temperature above $35^{\circ} \mathrm{C}$, which is above ocular temperature. 


\subsection{In vitro drug release studies}

In vitro release was evaluated for FA in situ gels of F3+FA, F4+FA, and a commercial product. This study was performed with simulated tear fluid ( $\mathrm{pH} \mathrm{7.4)}$ as release media at $32^{\circ} \mathrm{C}$ and the obtained results are shown in Figure 3. Within $1^{\text {st }}$ hour of the study, only $7-8 \%$ of the FA has been released as proof that gels can control the drug release. After $1 \mathrm{~h}$, the release rate was progressively increased. At the end of the $12 \mathrm{~h}$, in vitro FA release from F3+FA, F4+FA, and the commercial product were found as $68.6 \%, 64.6 \%, 90.3 \%$ respectively. Accordingly, it can be said that F3 and F4 formulations provided sustained drug release for a period of $12 \mathrm{~h}$. F3+FA formulation showed higher release than the F4 formulation which can be attributed to the higher ratio of $\mathrm{NaCMC}$. Approximate $100 \%$ of the FA was released from F3+FA, F4+FA, and the commercial product within $24 \mathrm{~h}$.

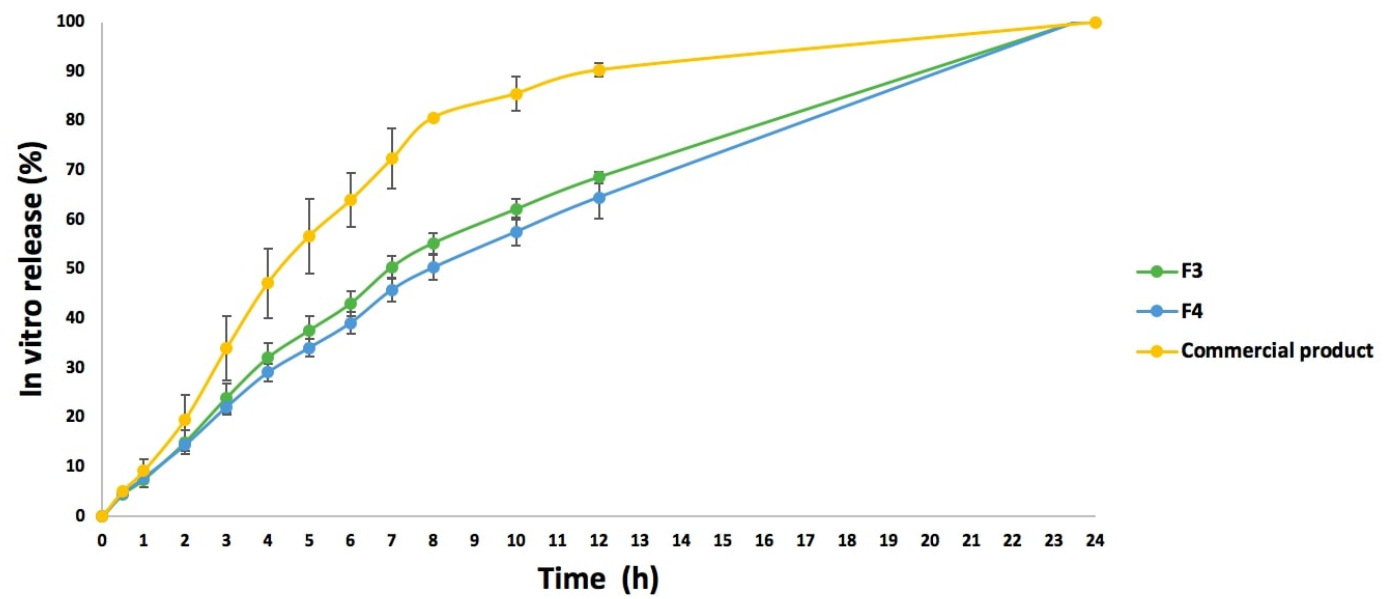

Figure 3.In vitro drug release profiles of fusidic acid loaded in situ gel formulations (F3 and F4) and commercial product $(n=3, \pm S D)$.

\subsection{Kinetic analysis}

The data obtained from in vitro release experiments of F3 and F4 in situ gels were assessedaccording to kinetic models (zero-order, first-order, Higuchi, and Hixson Crowell and Korsmeyer-Peppas). The release data of FA from F3 and F4 gels were fitted to the first-order and Hixson Crowell followed by Higuchi models. First-order, Hixson Crowell and Higuchi models would be suitable because the $\mathrm{r}^{2}$ values were so close to each other (Table 4).

Release kinetics of FA loaded in situ gel formulations were also evaluated according to the KorsmeyerPeppas model. $n=0.5$ is for Fickian diffusion; $n=1$ indicates zero-order (the release rate is independent of time, case II transport); and $0.5<\mathrm{n}<1.0$, means diffusion and non-Fickian transport are implicated. Also, when $n>1.0$ super case II transport is apparent ' $n$ ' is the slope value of $\log m_{t} / m_{\infty}$ versus $\log$ time curve[39]. The $n$ value of the F3 and F4 gels was determined as 0.6845 and 0.3675 , respectively (Table 4).

Table 4. Kinetic data of fusidic acid.

\begin{tabular}{|c|c|c|c|c|c|c|c|c|c|c|c|c|c|c|}
\hline \multirow{2}{*}{ Formulation } & \multicolumn{3}{|c|}{ Zero order } & \multicolumn{3}{|c|}{ First order } & \multicolumn{3}{|c|}{ Higuchi } & \multicolumn{3}{|c|}{ Hixson Crowell } & \multicolumn{2}{|c|}{$\begin{array}{c}\text { Korsmeyer- } \\
\text { Peppas }\end{array}$} \\
\hline & $\mathrm{r}^{2}$ & n & m & $\mathrm{r}^{2}$ & $\mathbf{n}$ & m & $\mathrm{r}^{2}$ & $\mathbf{n}$ & m & $\mathbf{r}^{2}$ & $\mathbf{n}$ & $\mathbf{m}$ & $\mathrm{r}^{2}$ & n \\
\hline F3 & 0.9711 & 5.4634 & 5.8201 & 0.9981 & 4.6222 & 0.0994 & 0.9919 & $\begin{array}{c}- \\
16.9387\end{array}$ & 24.8269 & 0.9941 & 0.0227 & 0.1275 & 0.9615 & 0.6845 \\
\hline F4 & 0.9810 & 5.1373 & 5.3617 & 0.9991 & 4.6128 & $\begin{array}{c}- \\
0.0870\end{array}$ & 0.9916 & $\begin{array}{c}- \\
15.2426 \\
\end{array}$ & 22.7517 & 0.9973 & 0.0276 & 0.1138 & 0.8663 & 0.3675 \\
\hline
\end{tabular}

\section{CONCLUSION}

In this study, fusidic acid loaded in situ gel formulations were successfully prepared and optimized as a function of different polymer ratios. F3+fusidic acid formulation was found to be an effective ophthalmic drug delivery system as indicated by appropriate rheological/mechanical properties and in vitro drug 
release. It can be concluded that PLX $407+\mathrm{NaCMC}$ based gel formulation containing fusidic acid can be an efficient alternative for the treatment of ocular bacterial conjunctivitis. However, further ex vivo and in vivo studies are required to confirm the results obtained in this study and these studies will be carried out.

\section{MATERIALS AND METHODS}

\subsection{Materials}

Poloxamer (PLX) 407 was provided by BASF Chemical Company (Germany). Fusidic acid (FA) was obtained from Berko İlaç ve Kimya Sanayi A.Ş. (Turkey). Sodium carboxymethyl cellulose (NaCMC) was purchased from Sigma-Aldrich (St. Louis, USA).

\subsection{Preparation of formulations}

In situ gels of FA were developed using PLX 407 as in situ gelling agent and NaCMC as a mucoadhesive agent. Gels were prepared by modification of the cold method [40,41]. Briefly, PLX 407 was added to the distilled water at $4^{\circ} \mathrm{C}$ and they were left at $4^{\circ} \mathrm{C}$ until a clear solution was obtained. Later, $\mathrm{NaCMC}$ was slowly added to these gels and they were left at room conditions for an additional $24 \mathrm{~h}$. Finally, $1 \%$ FA was added with strong stirring. The contents of prepared gels are presented in Table 5.All formulations were visually inspected for their homogeneity, appearance, and presence of any aggregate after they have been set in the container.

Table 5. The composition of the gels.

\begin{tabular}{lccc}
\hline Code & $\begin{array}{c}\text { PLX 407 } \\
(\%, \mathbf{w} / \mathbf{w})\end{array}$ & $\begin{array}{c}\text { NaCMC } \\
(\%, \mathbf{w} / \mathbf{w})\end{array}$ & FA (\%, w/w) \\
\hline F1 & 12 & 0.1 & - \\
F2 & 12 & 0.5 & - \\
F3 & 14 & 0.1 & - \\
F4 & 14 & 0.5 & - \\
F5 & 16 & 0.1 & - \\
F6 & 16 & 0.5 & - \\
F7 & 18 & 0.1 & - \\
F8 & 18 & 0.5 & - \\
F3+FA & 14 & 0.1 & 1 \\
F4+FA & 14 & 0.5 & 1 \\
\hline
\end{tabular}

\subsection{Determination of $\mathrm{pH}$}

Studies were carried outusing a $\mathrm{pH}$ meter (NEL Mod.821, Turkey) at room conditions to investigate the suitability of the prepared gels for ocular use.

\subsection{Measurement of gelation temperature}

The gelation temperature of gels was determined with a rheometer (TA Discovery HR-1 Hybrid Rheometer) and with a stainless-steel plate/plate probe. The sol-gel transition temperatures of the samples were performed from oscillation measurements by a fixed frequency of $0.01 \mathrm{~Hz}$. The gels were heated from $15^{\circ} \mathrm{C}$ to $50^{\circ} \mathrm{C}$ with a rate of $2^{\circ} \mathrm{C} / \mathrm{min}$ during the study.

\subsection{Rheological studies}

All rheological measurements were performed using a rheometer (TA Discovery HR-1 Hybrid Rheometer). Continuous shear analysis of each sample was studied, in flow mode and conjunction with parallel steel plate geometry ( $1 \mathrm{~mm}$ of the gap). Downward and upward and flow curves were measured ranging from $10 \mathrm{~s}^{-1}$ to $1000 \mathrm{~s}^{-1}$.

The rheological analysis of each formulation was performed after the determination of its linear viscoelastic region. Frequency sweep analysis was carried out over the frequency range of $0.1-10.0 \mathrm{~Hz}$ following the application of constant stress. The loss tangent ( $\tan \delta$ ), elastic (storage) modulus (G'), and viscous (loss) modulus (G") were determined. 


\subsection{Determination of mechanical properties}

Mechanical properties of gels were determined using a software-controlled penetrometer (TA-XT Plus Texture Analyser Stable Micro Systems, UK) equipped with a $0.5 \mathrm{~kg}$ load cell and $10 \mathrm{~mm}$ diameter analytical probe $(\mathrm{P} / 10)$ at $32^{\circ} \mathrm{C}$. Mechanical parameters (hardness, adhesiveness, compressibility, cohesiveness, and elasticity) were calculated from the obtained force-time curves. Experiments were carried out at least six times[42].

\subsection{In vitro drug release studies}

In vitro release study was performed in a mixture of ethanol and simulated tear fluid (20:80) at $50 \mathrm{rpm}$ $[1,43]$. The temperature was set at $32 \pm 0.5^{\circ} \mathrm{C}$ to mimic the eye temperature. Formulations were separated from release media using a dialysis membrane (standard regenerated cellulose tubing, MW of 12-14 kDa, Spectra/por Spectrum Chemical, U.S.)Samples were withdrawn at a planned time interval of $30 \mathrm{~min}$ to $24 \mathrm{~h}$ and the medium was replaced with the same volume [4]. The samples were analyzed with a UV spectrophotometer (UVmini-1240, Shimadzu, Japan) for the drug content. The assay was carried out at 232 $\mathrm{nm}$ and the dissolution medium was used as blind. The experiment was repeated three times [44].

\subsection{Kinetic analysis}

In vitro release values were performed with model-dependent methods [45]. A computer program prepared by Ege and coworkers [46] was applied to decide the suitable drug release kinetic model. The large value of the coefficient of determination $\left(\mathrm{r}^{2}\right)$ indicated supremacy of the dissolution behavior fitting to models. The release kinetics of the gel formulations were examined according to the following mathematical formulas:

$$
\begin{array}{lr}
\text { Zero-order model: } Q_{t}=Q_{0}+k_{0} t & \text { [Eq. 1] } \\
\text { First-order model: } Q_{t}=Q_{0} e^{-k t} & \text { [Eq. 2] } \\
\text { Higuchi's model: } Q_{t}=k_{H} t^{1 / 2} & \text { [Eq. 3] } \\
\text { Korsmeyer-Peppas model: } f_{t}=k_{m} t^{n} & \text { [Eq. 4] } \\
\text { Hixson-Crowell model: } Q_{0}^{1 / 3}-Q_{t}^{1 / 3}=k_{H C} t
\end{array}
$$

The $f_{t}$ represents the fraction of drug dissolved in time $\mathrm{t}, \mathrm{k}_{\mathrm{f}}, \mathrm{k}_{0}, \mathrm{k}_{\mathrm{H}}, \mathrm{k}_{\mathrm{m}}$, and $\mathrm{k}_{\mathrm{HC}}$ are the apparent constants of dissolution rate for the first-order, zero-order, Higuchi model Korsmeyer-Peppas model, and Hixson- Crowell model, respectively. In the case of Hixson-Crowell, zero order, first order, and Higuchi's model $Q_{0}$ is the initial amount of drug, $Q_{t}$ is the cumulative amount of drug release at time $t$. In the case of Korsmeyer- Peppas " $n$ " is the release exponent for Korsmeyer-Peppas (the value of exponent $n$ is used to characterize the mechanism for both solvent penetration and drug release[47,48].

\subsection{Statistical data analysis}

The analysis of statistical data was obtained with the Student's t-test by $\mathrm{P}<0.05$ as the minimal level of significance.

Acknowledgements: The authors would like to acknowledge to Berko İlaç for providing fusidic acid.

Author contributions:Concept - S.R., N.Ü.O., Z.A.Ş.; Design - S.R., N.Ü.O., Z.A.Ş.; Supervision - S.R., N.Ü.O., Z.A.Ş..; Resources - S.R., E.Ö.B., N.Ü.O., Z.A.Ş; Materials - S.R., E.Ö.B., N.Ü.O., Z.A.S.; Data Collection and/or Processing S.R., E.Ö.B., N.Ü.O., Z.A.S.; Analysis and/or Interpretation - S.R., E.Ö.B., N.Ü.O., Z.A.S.; Literature Search - S.R., E.Ö.B., N.Ü.O., Z.A.Ş.; Writing - S.R., E.Ö.B., N.Ü.O., Z.A.Ş.; Critical Reviews - S.R., E.Ö.B., N.Ü.O., Z.A.Ş.

Conflict of interest statement: The authors declared no conflict of interest. 


\section{REFERENCES}

[1] Üstündağ Okur N, Yozgatlı V, Okur ME, Yoltaş A, Siafaka PI. Improving Therapeutic Efficacy of Voriconazole Against Fungal Keratitis: Thermo-Sensitive In Situ Gels as Ophthalmic Drug Carriers. J Drug Deliv Sci Technol. 2019; 49: 323-333. [CrossRef]

[2] Üstündağ Okur N, Yoltas A, Yozgatli V. Development and Characterization of Voriconazole Loaded In Situ Gel Formulations for Ophthalmic Application. Turkish J Pharm Sci. 2016; 13: 311-317. [CrossRef]

[3] Okur ME, Ayla Ş, Batur Ş, Yoltaş A, Genç E, Pertek S, et al. Evaluation of In Situ Gel Containing Pycnogenol for Cutaneous Wound Healing. Medeniyet Med J. 2019; 34: 67-75.[CrossRef]

[4] Aksu NB, Yozgatlı V, Okur ME, Ayla Ş, Yoltaş A, Üstündağ Okur N. Preparation and Evaluation of QbD Based Fusidic Acid Loaded In Situ Gel Formulations for Burn Wound Treatment. J Drug Deliv Sci Technol. 2019; 52: 110121.[CrossRef]

[5] The International Pharmacopoeia - Ninth Edition - Ophthalmic Preparations. 2019.

[6] Sandle T. Sterile Ophthalmic Preparations and Contamination Control. J GXP Compliance. 2014; 18(3).

[7] Brun-Graeppi AKAS, Richard C, Bessodes M, Scherman D, Narita T, Ducouret G, et al. The Effect of Sterilization Methods on the Thermo-Gelation Properties of Xyloglucan Hydrogels. Polym Degrad Stab. 2010; 95(2): $254-259$. [CrossRef]

[8] Cooper RC, Yang H. Hydrogel-Based Ocular Drug Delivery Systems: Emerging Fabrication Strategies,Applications, and Bench-to-Bedside Manufacturing Considerations. J Control Release. 2019; 306: 29-39. [CrossRef]

[9] Aldrich DS, Bach CM, Brown W, Chambers W, Fleitman J, Hunt D, et al. Ophthalmic Preparations. Stimuli to Revis Process. 2013; 39(5): 1-21.

[10] Imperiale JC, Acosta GB, Sosnik A. Polymer-Based Carriers for Ophthalmic Drug Delivery. J Control Release. 2018; 285: 106-141. [CrossRef]

[11] Galante R, Pinto TJA, Colaço R, Serro AP. Sterilization of Hydrogels for Biomedical Applications: A Review. J Biomed Res. 2018; 106(6): 2472-2492.

[12] Soliman KA, Ullah K, Shah A, Jones DS, Singh TRR. Poloxamer-Based In Situ Gelling Thermoresponsive Systems for Ocular Drug Delivery Applications. Drug Discov Today. 2019; 24(8): 1575-1586. [CrossRef]

[13] Lihong W, Xin C, Yongxue G, Yiying B, Gang C. Thermoresponsive Ophthalmic Poloxamer/Tween/Carbopol In Situ Gels of a Poorly Water-Soluble Drug Fluconazole: Preparation and In Vitro - In Vivo Evaluation. Drug Dev Ind Pharm. 2014; 40: 1402-1410.[CrossRef]

[14] Asasutjarit R, Thanasanchokpibull S, Fuongfuchat A, Veeranondha S. Optimization and Evaluation of Thermoresponsive Diclofenac Sodium Ophthalmic In Situ Gels. Int J Pharm. 2011; 411(1-2): 128-135. [CrossRef]

[15] Tayel SA, El-Nabarawi MA, Tadros MI, Abd-Elsalam WH. Promising Ion-Sensitive In Situ Ocular Nanoemulsion Gels of Terbinafine Hydrochloride: Design, In Vitro Characterization and In Vivo Estimation of the Ocular Irritation and Drug Pharmacokinetics in the Aqueous Humor of Rabbits. Int J Pharm. 2013; 443(1-2): $293-305$. [CrossRef]

[16] Burak J, Grela KP, Pluta J, Karolewicz B, Marciniak DM. Impact of Sterilisation Conditions the Rheological Properties of Thermoresponsive Pluronic F-127-Based Gels for the Ophthalmic Use. Acta Pol Pharm - Drug Res 2018; 75(2): 471-481.

[17] Ni J, Guo M, Cao Y, Lei L, Liu K, Wang B, et al. Discovery, Synthesis of Novel Fusidic Acid Derivatives Possessed Amino-Terminal Groups at the 3-Hydroxyl Position with Anticancer Activity. Eur J Med Chem. 2019; 162: $122-131$. [CrossRef]

[18] Akinpelu OI, Lawal MM, Kumalo HM, Mhlongo NN. Drug Repurposing : Fusidic Acid as a Potential Inhibitor of M . Tuberculosis FtsZ Polymerization - Insight from DFT Calculations, Molecular Docking and Molecular Dynamics Simulations. Tuberculosis. 2020; 121: 101920. [CrossRef]

[19] Okur ME, Ayla Ş, Yozgatlı V, Aksu NB, Yoltaş A, Orak D, et al. Evaluation of Burn Wound Healing Activity of Novel Fusidic Acid Loaded Microemulsion Based Gel in Male Wistar Albino Rats. Saudi Pharm J. 2020; 28 : 338-348. [CrossRef]

[20] Biedenbach DJ, Rhomberg PR, Mendes RE, Jones RN. Spectrum of Activity, Mutation Rates, Synergistic Interactions, and the Effects of $\mathrm{pH}$ and Serum Proteins for Fusidic Acid (CEM-102). Diagn Microbiol Infect Dis. 2010; 66(3): 301-307. [CrossRef] 
[21] Bochot A, Fattal E, Grossiord JL, Puisieux F, Couvreur P. Characterization of a New Ocular Delivery System Based on a Dispersion of Liposomes in a Thermosensitive Gel. Int J Pharm. 1998; 162: 119-127. [CrossRef]

[22] Youssef NAHA, Kassem AA, Farid RM, Ismail FA, EL-Massik MAE, Boraie NA. A Novel Nasal Almotriptan Loaded Solid Lipid Nanoparticles in Mucoadhesive In Situ Gel Formulation for Brain Targeting: Preparation, Characterization and In Vivo Evaluation. Int J Pharm. 2018; 548: 609-624. [CrossRef]

[23] Pagano C, Giovagnoli S, Perioli L, Tiralti MC, Ricci M. Development and Characterization of MucoadhesiveThermoresponsive Gels for The Treatment of Oral Mucosa Diseases. Eur J Pharm Sci. 2020; 142: 105125. [CrossRef]

[24] Makwana SB, Patel VA, Parmar SJ. Development and Characterization of In-Situ Gel for Ophthalmic Formulation Containing Ciprofloxacin Hydrochloride. Results Pharma Sci. 2016; 6: 1-6. [CrossRef]

[25] Pawar SD, Pawar RG, Gadhave M V., Jadhav SL, Gaikwad DD. Controlled Release In Situ Forming Gatifloxacin HCL Hydrogel for Ophthalmic Drug Delivery. Int Res J Pharm. 2012; 3: 86-89.

[26] Patel N, Thakkar V, Metalia V, Baldaniya L, Gandhi T, Gohel M. Formulation and Development of Ophthalmic In Situ Gel for the Treatment Ocular Inflammation and Infection Using Application of Quality by Design Concept. Drug Dev Ind Pharm. 2016; 42: 1406-1423.[CrossRef]

[27] Güven UM, Berkman MS, Şenel B, Yazan Y. Development and In Vitro/In Vivo Evaluation of Thermo-Sensitive In Situ Gelling Systems for Ocular Allergy. Brazilian J Pharm Sci. 2019; 55: 1-11. [CrossRef]

[28] Karatas A, Boluk A, Hilal Algan A. Poloxamer/Chitosan In Situ Gelling System for Ocular Delivery of Ofloxacin. Curr Drug Ther. 2014; 9(4): 219-225. [CrossRef]

[29] Yu ZG, Geng ZX, Liu TF, Jiang F. In Vitro and In Vivo Evaluation of an In Situ Forming Gel System for Sustained Delivery of Florfenicol. J Vet Pharmacol Ther. 2015; 38: 271-277.

[30] Li L, Guo D, Guo J, Song J, Wu Q, Liu D, et al. Thermosensitive In-Situ Forming Gels for Ophthalmic Delivery of Tea Polyphenols. J Drug Deliv Sci Technol. 2018; 46: 243-250.[CrossRef].

[31] Rençber S, Karavana SY, Şenyiğit ZA, Eraç B, Limoncu MH, Baloğlu E. Mucoadhesive In Situ Gel Formulation for Vaginal Delivery of Clotrimazole: Formulation, Preparation, and In Vitro/In Vivo Evaluation. Pharm Dev Technol. 2017; 22(4): 551-561. [CrossRef]

[32] Chang JY, Oh YK, Choi H gon, Kim YB, Kim CK. Rheological Evaluation of Thermosensitive and Mucoadhesive Vaginal Gels in Physiological Conditions. Int J Pharm. 2002; 241(1): 155-163. [CrossRef]

[33] Kaur H, Loyee S, Garg R. Formulation and Evaluation of In-Situ Ocular Gel of Gatifloxacin. Int J Pharma Res Heal Sci. 2016;4(5):1365-1370. [CrossRef]

[34] Mandal S, Thimmasetty MK, Prabhushankar G, MS G. Formulation and Evaluation of an In Situ Gel-Forming Ophthalmic Formulation of Moxifloxacin Hydrochloride. Int J Pharm Investig. 2012; 2(2): 78-82. [CrossRef]

[35] Swain GP, Patel S, Gandhi J, Shah P. Development of Moxifloxacin Hydrochloride Loaded In-Situ Gel for the Treatment of Periodontitis: In-Vitro Drug Release Study and Antibacterial Activity. J Oral Biol Craniofacial Res. 2019; 9(3): 190-200. [CrossRef]

[36] Baloglu E, Karavana SY, Senyigit ZA, Guneri T. Rheological and Mechanical Properties of Poloxamer Mixtures as a Mucoadhesive Gel Base. Pharm Dev Technol. 2011; 16(6): 627-636. [CrossRef]

[37] Baloglu E, Karavana SY, Senyigit ZA, Hilmioglu-Polat S, Metin DY, Zekioglu O, et al. In-Situ Gel Formulations of Econazole Nitrate: Preparation and In-Vitro and In-Vivo Evaluation. J Pharm Pharmacol. 2011; 63: $1274-1282$. [CrossRef]

[38] Abouhussein DMN, Khattab A, Bayoumi NA, Mahmoud AF, Sakr TM. Brain Targeted Rivastigmine Mucoadhesive Thermosensitive In Situ Gel: Optimization, In Vitro Evaluation, Radiolabeling, In Vivo Pharmacokinetics and Biodistribution. J Drug Deliv Sci Technol. 2018; 43: 129-140. [CrossRef]

[39] Siafaka P, Okur ME, Ayla Ş, Er S, Cağlar EŞ, Okur NÜ. Design and Characterization of Nanocarriers Loaded with Levofloxacin for Enhanced Antimicrobial Activity; Physicochemical Properties, In Vitro Release and Oral Acute Toxicity. Brazilian J Pharm Sci. 2019; 55: 1-13. [CrossRef]

[40] Bilensoy E, Rouf MA, Vural I, Şen M, Hıncal AA. Mucoadhesive, Thermosensitive, Prolonged-Release Vaginal Gel for Clotrimazole : $\beta$-Cyclodextrin Complex. AAPS PharmSciTech. 2006; 7(2): 1-7. [CrossRef]

[41] Choi HG, Jung JH, Ryu JM, Yoon SJ, Oh YK, Kim CK. Development of In Situ-Gelling and Mucoadhesive Acetaminophen Liquid Suppository. Int J Pharm .1998; 165(1): 33-44. [CrossRef]

[42] Jones DS, Woolfson AD, Djokic J. Texture Profile Analysis of Bioadhesive Polymeric Semisolids: Mechanical 
Characterization and Investigation of Interactions Between Formulation Components. J Appl Polym Sci. 1996 ;61(12): 2229-2234. [CrossRef]

[43] Üstündağ-Okur N, Gökçe EH, Bozbiyik DI, Eğrilmez S, Özer Ö, Ertan G. Preparation and In Vitro-In Vivo Evaluation of Ofloxacin Loaded Ophthalmic Nano Structured Lipid Carriers Modified with Chitosan Oligosaccharide Lactate for the Treatment of Bacterial Keratitis. Eur J Pharm Sci. 2014; 63: 204-215. [CrossRef]

[44] Özcan Bülbül E, Mesut B, Cevher E, Öztaş E, Özsoy Y. Product Transfer from Lab-Scale to Pilot-Scale of Quetiapine Fumarate Orodispersible Films Using Quality by Design Approach. J Drug Deliv Sci Technol. 2019; 54: 101358. [CrossRef]

[45] Dash S, Murthy PN, Nath L, Chowdhury P. Kinetic Modeling on Drug Release from Controlled Drug Delivery Systems. Acta Pol Pharm - Drug Res. 2010; 67: 217-223.

[46] Aksu B, Yurdasiper A, Ege MA, Okur NÜ, Karasulu HY. Development and Comparative Evaluation of Extended Release Indomethacin Capsules. African J Pharm Pharmacol. 2013; 7(30): 2201-2209.

[47] Costa P, Lobo JMS. Modeling and Comparison of Dissolution Profiles. Eur J Pharm Sci. 2001; 13(2): 123-133. [CrossRef]

[48] Üstündağ Okur N, Filippousi M, Okur ME, Ayla Ş, Çağlar EŞ, Yoltaş A, et al. A Novel Approach for Skin Infections: Controlled Release Topical Mats of Poly(Lactic Acid)/Poly(Ethylene Succinate) Blends Containing Voriconazole. J Drug Deliv Sci Technol. 2018; 46: 74-86. [CrossRef]

This is an open access article which is publicly available on our journal's website under Institutional Repository at http://dspace.marmara.edu.tr. 